\title{
Barriers to Contraceptive Uptake among Women of Reproductive Age in a Semi-Urban Community of Ekiti State, Southwest Nigeria
}

\author{
Kabir A. Durowade ${ }^{1 *}$, Lukman O. Omokanye ${ }^{2}$, Olusegun E. Elegbede ${ }^{1}$,Stella \\ Adetokunbo ${ }^{1}$, Charles O. Olomofe ${ }^{1}$, Akinyosoye D. Ajiboye ${ }^{2}$, Makinde A. \\ Adeniyi ${ }^{1}$, Taofik A. Sanni ${ }^{1}$
}

OPEN ACCESS

Citation: Kabir A. Durowade, Lukman O. Omokanye, Olusegun E. Elegbede, Stella Adetokunbo, Charles O. Olomofe, Akinyosoye D. Ajiboye, Makinde A. Adeniyi', Taofik A. Sanni.. Barriers to Contraceptive Uptake among Women of Reproductive Age in a Semi-Urban Community of Ekiti State, Southwest Nigeria. Ethiop J Health Sci 2017;27(1):121. doi: http://dx.doi.org/10.4314/ejhs.v27i2.4

Received: October 2, 2016

Accepted: November 9, 2016

Published: March 1, 2017

Copyright: () 2015 Durowade KA., et al. This is an open access article distributed under the terms of the Creative Commons Attribution License, which permits unrestricted use, distribution, and reproduction in any medium, provided the original author and source are credited. Funding: Nill

Competing Interests: The authors declare that this manuscript was approved by all authors in its form and that no competing interest exists.

Affiliation and Correspondence:

${ }^{1}$ Department of Community Medicine,

Federal Teaching Hospital, Ido-Ekiti,

Ekiti State, Nigeria

${ }^{2}$ Department of Obstetrics and

Gynaecology, University of Ilorin,

Ilorin, Nigeria

"Email: kadurowade@yahoo.com

\section{ABSTRACT}

BACKGROUND: Globally, unplanned pregnancy and sexually transmitted infections (STIs) persist as a significant threat to women's reproductive health. In Nigeria, despite huge resources committed to family planning programs by stakeholders, contraceptive use has been very low. This study aimed at unraveling the barriers to the use of modern contraceptives among women of reproductive age (15-49 years) in Ise-Ekiti community, Ekiti State, Southwest Nigeria.

METHODS: This study was a cross sectional study among women aged 15-49 years. A multi-stage sampling technique was used in the recruitment of respondents from the community. An interviewer-administered questionnaire was used to collect data. Data were analyzed using SPSS version 15.

RESULTS: Although contraceptive awareness among respondents was high 496(98.6\%), only 254 of the 503 respondents were using modern contraceptive methods giving a Contraceptive Prevalence Rate (CPR) of 50.5\%. Among those not using any form of contraceptives, some identifiable barriers to contraceptive use includes desire for more children, 62(39.5\%), partner disapproval, 40(25.5\%), and fear of side-effects, 23(14.6\%). Factors associated with contraceptive uptake include marital status ( $p=0.028)$, educational level $(p=0.041)$ and religion $(p=0.043)$ with traditional worshippers having the least uptake.

CONCLUSION: This study showed that awareness to modern forms of contraceptives does translate into use. The identified barriers to contraceptive uptake suggest the need to improve uptake of contraceptives through a community-based and culturally acceptable intervention as doing this will go a long way in addressing some of these barriers.

KEYWORD: Contraceptives uptake, barriers, women of reproductive age 


\section{INTRODUCTION}

Contraceptive methods are preventive methods which help women avoid unwanted pregnancies (1). They include all temporary and permanent measures to prevent pregnancy resulting from coitus (1). Although family planning is not synonymous with birth control, planning, provision and use of birth control are called family planning methods (1). Some contraceptives prevent against sexually transmitted infections (STI). Within the same society, contraception varies amongst people of different socio-cultural, educational, religious or occupational affiliations (2). Family planning was cited as essential to the achievement of the erstwhile millennium development goals (MDG) because it has a direct impact on women's health and consequences on each pregnancy (3). It is believed that high fertility dis-empowers women (4). Globally, unplanned pregnancies and STI persist as significant threats to women's reproductive health (5).

The level of awareness to contraceptive varies from place to place. Among Nigerian bankers aged 21-45 years, it showed that about a $100 \%$ of them are aware of at least one method of contraception (2). A similar study in Osogbo, Nigeria put the awareness of modern contraceptives to be $90.3 \%$ among respondents with a mean age of $28.6 \pm 6.65$ years (6). A study among Ethiopian adults showed a high knowledge of contraceptives among respondents (7).

Studies in Africa identified barriers like the fear of side-effects $(44.0 \%)$, ignorance $(32.0 \%)$, misinformation $(25.1 \%)$, superstition $(22.0 \%)$ and culture $(20.3 \%)$ (6). Other studies identified poor spousal contraceptive communications (4), financial constraints and regional barriers and lack of access to services. Similar studies around the world identified poor health services, poor knowledge of methods (3) and provider-related barriers to its provision (8). This study aimed to determine the awareness, knowledge and barriers to contraceptive uptake among adults in Ise-Ekiti, Ekiti state, Southwest Nigeria.

\section{METHODS}

Ise-Ekiti, headquarter of Ise/Orun Local Government Area (LGA) of Ekiti State, is located in the Southwestern part of Nigeria. The community is located within the tropics and geographically positioned near the equator. With an annual growth rate of $3.2 \%$, the projected population of Ise-Ekiti is 254,350 . Ise/Orun LGA has 10 wards of which eight are in Ise-Ekiti and are numbered 1-8. The remaining two wards are in Orun.The people of Ise-Ekiti speak the Ekiti dialect of the Yoruba language and are predominantly farmers. However, few people are engage in vocational services. Most people practice Christianity and Islam while some are traditional worshippers.

Grand multi-parity and high teenage pregnancies are a common sight. They also account for the high maternal morbidity and mortality during pregnancy, delivery and pueperium. There is also a high rate of neonatal and infant mortality. Worse still, access to family commodities is poor in the community.

This study was a descriptive/cross sectional study to identify barriers to contraceptive uptake among adults in Ise-Ekiti, Ise/Orun Local Government Area, Ekiti State.The minimum sample size was determined using Fisher's formula $\left(n=Z^{2} \mathrm{pq} / \mathrm{d}^{2}\right)$ for estimating sample size where the population is greater than 10,000 $(10,11)$. A sample size of 345 was used for the study. A multistage sampling technique with four stages was used to select the respondents for the study.

Stage 1: Simple random sampling technique by balloting was used to select four wards out of the eight wards in Ise-Ekiti.

Stage 2: Simple random sampling technique by balloting was used to select two communities each from the selected four wards. Consequently, a total of eight communities were selected.

Stage 3: The communities were delineated into Enumeration Areas (EAs) with each comprising 44 households. Cluster sampling technique was used to select respondents in the enumeration areas. Households in the EAs were visited. Each EA was regarded as a cluster, all eligible and willing respondents were recruited into the study. Consequently, as a result of the use of cluster sampling technique, a correction factor of 1.2 was used to increase the computed sample size. This gave a sample size of 414. However, a total of 503

DOI: http://dx.doi.org/10.4314/ejhs.v27i2.4 
subjects were interviewed as eligible, and willing respondents were selected in each household.

Interviewer-administered, semi-structured questionnaire was used to elicit the study subjects' socio-demographics, awareness, knowledge and barriers to contraceptive uptake among the respondents.The questionnaire was pre-tested in Orun community, another community in Ise/Orun Local Government Area of Ekiti State, which is about 60 kilometers from Ise-Ekiti. This was done to detect deficiencies or ambiguities in the questionnaire and making appropriate correction.

Four research assistants also participated in the study. They were resident doctors trained on data collection using interviewer-administered questionnaire. Data collation and editing were done manually to detect omission and ensure uniform coding.

The analysis was done using SPSS version 15; frequency tables and cross-tabulations were generated to show the association between the socio-demographic variables and barriers to uptake of contraceptives among the respondents. Univariate and Bivariate analyses were employed to analyze the data . Chi-square test was used to determine statistical significance of observed differences in the cross- tabulated variables.

Ethical approval for the study was obtained from the Research and Ethical Committee of the Federal Teaching Hospital, Ido-Ekiti. Informed consent was obtained from the participants after the nature of the research was explained to them. Anonymity and confidentiality of the respondents' responses were ensured and guaranteed.

\section{RESULTS}

The total number of women interviewed was 503, and as shown in Table 1, a total of 411(81.7\%) were married and others were single, $81(16.1 \%)$, divorced, 7(1.4\%), and separated, 4(0.8\%). Also as seen in Table 1, the levels of education of the women were no formal education, 22 (4.4\%), primary, 84 (16.7\%), secondary, $239(47.5 \%)$ and tertiary, $158(31.4 \%)$. As shown in Table 2, 496 (98.6\%) respondents had ever heard contraceptive before, while only 7 (1.4\%) had not. The common contraceptives ever heard about by the women include male condom, natural methods, pills and injectables, IUCD with 491 (99\%), 457 (92.1\%), 449 (90.5\%), 426 (85.9\%) and 275 (55.4\%), respectively.

In Table 3, the number of women that said family planning commodities were readily available were $381(71.5 \%)$ but $122(24.3 \%)$ insist commodities were not readily available. Those that considered the family planning services out of reach suggest; health education 61 (50\%), improved supplies $35(28.1 \%)$ and reduction in prices $26(21.3 \%)$ as possible ways to increase availability of the commodities.

As shown in Table 4, 346 (68.8\%) women had ever used one form of contraceptive while 157 $(31.2 \%)$ had never used any form of family planning. Also in Table 4, duration of use among those who had used contraceptives was less than 1 year, 82 (23.7\%), 1-2 years, $124(35.8 \%), 3-5$ years, $87(25.2 \%)$ and above 5 years, $53(15.3 \%)$. Their reasons for using contraceptives were prevention of unwanted pregnancy, 276 (79.8\%), suitability and reliability of methods, 192 (55.5\%), accessibility, 170 (49.1\%), affordability, $106(30.6 \%)$ and little or no side effect, 63 $(18.2 \%)$.

As presented in Table 5, respondents' marital status $(\mathrm{p}=0.028)$, religion $(\mathrm{p}=0.043)$ and level of education ( $\mathrm{p}=0.041)$ were found to be significantly associated with uptake of contraception.

DOI: http://dx.doi.org/10.4314/ejhs.v27i2.4 
Table 1: Socio-demographic Characteristics of respondents

\begin{tabular}{|c|c|c|c|}
\hline Variable & & $\begin{array}{l}\text { Frequency } \\
\mathbf{N}=\mathbf{5 0 3}\end{array}$ & Percentage \\
\hline \multicolumn{4}{|l|}{ Age } \\
\hline & Less than 20 & 71 & 14.1 \\
\hline & $20-24$ & 82 & 16.4 \\
\hline & $25-29$ & 112 & 22.2 \\
\hline & $30-34$ & 101 & 20.1 \\
\hline & 35 and above & 137 & 27.2 \\
\hline \multicolumn{4}{|c|}{ Marital Status } \\
\hline & Single & 81 & 16.1 \\
\hline & Married & 411 & 81.7 \\
\hline & Divorced/ Separated & 7 & 1.4 \\
\hline & Widowed & 4 & 0.8 \\
\hline \multicolumn{4}{|l|}{ Religion } \\
\hline & Christianity & 358 & 71.2 \\
\hline & Islam & 136 & 27.0 \\
\hline & Traditional & 9 & 1.8 \\
\hline \multicolumn{4}{|l|}{ Ethnicity } \\
\hline & Yoruba & 488 & 97.0 \\
\hline & Non Yoruba & 15 & 3.0 \\
\hline \multicolumn{4}{|c|}{ Level of Education } \\
\hline & No formal education & 22 & 4.4 \\
\hline & Primary & 84 & 16.7 \\
\hline & Secondary & 239 & 47.5 \\
\hline & Tertiary & 158 & 31.4 \\
\hline \multicolumn{4}{|c|}{ Occupation } \\
\hline & Civil Servant & 171 & 34.0 \\
\hline & Self employed & 242 & 48.1 \\
\hline & Student & 84 & 16.7 \\
\hline & Unemployed & 6 & 1.2 \\
\hline
\end{tabular}

Table 2: Awareness of Contraception among respondents

\begin{tabular}{cll}
\hline Variable & $\begin{array}{c}\text { Frequency } \\
\mathbf{N = 5 0 3}\end{array}$ & Percentage \\
\hline Ever heard of contraception & & \\
Yes & 496 & 98.6 \\
No & 7 & 1.4 \\
Sources of information* $(\mathbf{n}=\mathbf{4 9 6})$ & 356 & 71.8 \\
Health worker & 248 & 50.0 \\
Friend/ Relative & 215 & 43.4 \\
Mass media (radio, TV, Newspaper etc) & 148 & 29.8 \\
School & 52 & 10.5 \\
Neighbour & & \\
Male condom & 491 & 99.0 \\
Natural & 457 & 92.1 \\
Pills & 449 & 90.5 \\
Injectibles & 426 & 85.9 \\
IUCD & 275 & 55.4 \\
Female condom & 55 & 11.1 \\
Traditional & 51 & 10.3 \\
\hline
\end{tabular}

*Multiple responses

DOI: http://dx.doi.org/10.4314/ejhs.v27i2.4 
Table 3: Availability of contraceptive commodities

\begin{tabular}{clll}
\hline Variable & $\begin{array}{c}\text { Frequency } \\
\text { N= 503 }\end{array}$ & Percentage \\
\hline FP commodities readily available? & 381 & 75.7 \\
Yes & 122 & 24.3 \\
No & & \\
How to improve the availability (n= 122) & 61 & 50.0 \\
Health education (to improve utilization) & 35 & 28.7 \\
Improved supply/access & 26 & 21.3 \\
Govt should reduce price & & \\
\hline
\end{tabular}

Table 4: Contraceptive uptake and its identified barriers among the respondents

\begin{tabular}{|c|c|c|}
\hline Variable & $\begin{array}{l}\text { Frequency } \\
\mathbf{N}=\mathbf{5 0 3}\end{array}$ & Percentage \\
\hline \multicolumn{3}{|l|}{ Using any form of contraception } \\
\hline Yes & 346 & 68.8 \\
\hline No & 157 & 31.2 \\
\hline \multicolumn{3}{|l|}{ What form of contraception $(n=346)$} \\
\hline Modern methods & 254 & 73.4 \\
\hline Natural methods & 90 & 26.0 \\
\hline Traditional methods & 2 & 0.6 \\
\hline \multicolumn{3}{|l|}{ How long in years $(n=346)$} \\
\hline Less than 1 & 82 & 23.7 \\
\hline $1-2$ & 124 & 35.8 \\
\hline $3-5$ & 87 & 25.2 \\
\hline Above 5 & 53 & 15.3 \\
\hline \multicolumn{3}{|l|}{ Reasons for using FP $(n=346)$} \\
\hline Prevent unwanted pregnancy & 276 & 79.8 \\
\hline Suitable and reliable & 192 & 55.5 \\
\hline Accessible & 170 & 49.1 \\
\hline Affordable & 106 & 30.6 \\
\hline Little or no side effects & 63 & 18.2 \\
\hline \multicolumn{3}{|l|}{ Reasons for not using FP (n=157) } \\
\hline No reason & 71 & 45.2 \\
\hline Desirous of more children & 62 & 39.5 \\
\hline Husband's disapproval & 40 & 25.5 \\
\hline Side effects & 23 & 14.6 \\
\hline Against my culture & 11 & 7.0 \\
\hline Not aware & 7 & 4.5 \\
\hline
\end{tabular}

DOI: http://dx.doi.org/10.4314/ejhs.v27i2.4 
Table 5: Relationship between socio-demographic characteristics and contraceptive uptake

\begin{tabular}{|c|c|c|c|c|c|}
\hline \multirow[b]{2}{*}{ Variable } & \multicolumn{2}{|c|}{ Using any form of contraception } & \multirow[b]{2}{*}{ Total } & \multirow[b]{2}{*}{$\chi^{2}$} & \multirow[b]{2}{*}{ p - value } \\
\hline & $\begin{array}{l}\text { Yes }(\%) \\
n=346\end{array}$ & $\begin{array}{l}\text { No (\%) } \\
n=157 \\
\end{array}$ & & & \\
\hline Age & & & & 2.9 & 0.564 \\
\hline Less than 20 & $48(67.6)$ & $23(32.4)$ & $71(100.0)$ & & \\
\hline $20-24$ & $56(68.3)$ & $26(31.7)$ & $82(100.0)$ & & \\
\hline $25-29$ & $83(74.1)$ & 29 (25.9) & $112(100.0)$ & & \\
\hline $30-34$ & $71(70.3)$ & $30(29.7)$ & $101(100.0)$ & & \\
\hline 35 and above & $88(64.2)$ & $49(35.8)$ & $137(100.0)$ & & \\
\hline Marital Status & & & & 9.1 & 0.028 \\
\hline Single & $54(66.7)$ & $27(33.3)$ & $81(100.0)$ & & \\
\hline Married & $286(69.6)$ & $125(30.4)$ & $411(100.0)$ & & \\
\hline Divorced/ Separated & $5(71.4)$ & $2(28.6)$ & $7(100.0)$ & & \\
\hline Widowed & $0(0.0)$ & $4(100.0)$ & $4(100.0)$ & & \\
\hline Religion & & & & 6.3 & 0.043 \\
\hline Christianity & $253(70.7)$ & $105(29.3)$ & $358(100.0)$ & & \\
\hline Islam & $90(66.2)$ & $46(33.8)$ & $136(100.0)$ & & \\
\hline Traditional & $3(33.3)$ & $6(66.7)$ & $9(100.0)$ & & \\
\hline Ethnicity & & & & 0.6 & $0.572 *$ \\
\hline Yoruba & $337(69.1)$ & $151(30.9)$ & $488(100.0)$ & & \\
\hline Non Yoruba & $9(60.0)$ & $6(40.0)$ & $15(100.0)$ & & \\
\hline Level of Education & & & & 8.3 & 0.041 \\
\hline No formal education & $10(45.5)$ & $12(54.5)$ & $22(100.0)$ & & \\
\hline Primary & $53(63.1)$ & $31(36.9)$ & $84(100.0)$ & & \\
\hline Secondary & $164(68.6)$ & $75(31.4)$ & $239(100.0)$ & & \\
\hline Tertiary & $116(73.4)$ & $42(26.6)$ & $158(100.0)$ & & \\
\hline Occupation & & & & 2.4 & 0.497 \\
\hline Civil Servant & $121(70.8)$ & $50(29.2)$ & $171(100.0)$ & & \\
\hline Self employed & $159(65.7)$ & $83(34.4)$ & $242(100.0)$ & & \\
\hline Student & $62(74.1)$ & $22(25.9)$ & $84(100.0)$ & & \\
\hline Unemployed & $4(66.7)$ & $2(33.3)$ & $6(100.0)$ & & \\
\hline
\end{tabular}

*Fisher exact test

\section{DISCUSSION}

This study shows average utilization of modern methods of contraception despite a near total awareness of family planning and contraception. The majority (98.6\% ) of the clients knew at least one form of contraception. This is similar to findings in other studies carried out within and outside of the country (9). The knowledge of various modern methods were very high except for the female condom which was low (11.1\%).

The group of women who had no reason for not using any contraception was surprisingly the highest. This accounted for $45.2 \%$ of those using contraceptives. This may be due to misconceptions that are yet unresolved in the minds of the respondents (10). It could also be that the women may consider their reasons too private to be discussed with anyone, which is common among teenagers and unmarried women (12). The group of women who desired more children was $39.5 \%$ and this can be explained by the prevailing mindset of people living in Sub-Saharan Africa about child-bearing. This includes desire for a large family size, desire for a specific number of children of a particular gender and sense of

DOI: http://dx.doi.org/10.4314/ejhs.v27i2.4 
accomplishment that is derived from having many children $(13,14)$. Lack of spousal support for utilizing contraception also featured strongly. The typical woman in Sub-saharan Africa still relies on the husband for key decision making including healthcare. This is because she may not be empowered economically to take such decisions by herself despite concerted efforts by the World Health organization and United Nations (16). The fear of side-effects of contraceptive use did not rank high in our study unlike findings in similar studies in Kenya, where such concerns ranked second. However, the fears that many women raised include fear of menstrual irregularities, delay in return to fertility, weight gain, congenitally malformed babies and inability to breastfeed babies when they are born (16-18).

The findings that utilization was higher among Christians than those practicing Islam show the effect of religion on contraceptive use. This has been found in similar studies $(16,19)$. Utilization was also found to be higher among those with formal education than those without any education. It is higher among those with primary level of education and the self- employed and civil-servants unlike those with no employment.Social class and education were found to correlate positively with contraceptive uptake in similar studies $(12,20,21)$.

This study, unlike many studies from other regions, did not show some other reasons for contraceptive non-use which include lack of sexual intercourse or infrequent sexual intercourse which was seen in women interviewed in Nepal and Bangladesh. The inability to volunteer such information may stem from the fact that discussions about sex in considered private.

Our findings show that a lot of women get information about contraception from health workers. However, half of these women equally obtain the information from friends and relations. This source of information may involve dissemination of a lot of misconceptions, which will not guide appropriate decision-making regarding family planning.

The implication of the findings is that much advocacy on use of modern methods of family planning. Family planning serves as a way of improving the socio-economic well-being of any society and is also pivotal in reducing the incidence of abortions and its complications.

There is a need to unravel why women refuse contraception for no reason. When such reasons are known, the women can be helped much better. As it is seen in this study, the awareness of modern family planning methods does not translate into use. There are a lot of obstacles to the use stemming from misconceptions. The campaigns for family planning services should aim at the misconceptions in order to drive the demand and remove the barriers. The influence of the male partner should also be considered, and more male friendly services should be incorporated into the practice of family planning.

\section{REFERENCES}

1. Park K. Demography and Family Planning. In: Park's Textbook of Preventive and Social Medicine. $\quad 19^{\text {th }}$ ed. India: M/s BanarsidasBhanot Publishers; 2007: 389-92

2. Ijeoma AM, Emmanuel CO, Anthony OM. Contraceptives among bankers in an urban community in Lagos state,Nigeria, Pan Afri Med Journal 2013;14(1):80-84

3. Najafi-sharjabad F, Zainiyah S Y S, Abdul R $\mathrm{H}$, Hanafiah J M, Abdul M R. Barriers to modern contraceptives practices among Asian women: a mini literature review, Glob $J$ Health Sci 2013; 22 (5):181-92.

4. Izugbara C, Ibisomi L, Ezeh A C, Mandar M, Gendered interest and poor spousal contraceptive communication Islamic northern Nigeria, J Fam Plan Reprod Care 2010; 36(4):219-24.

5. Randrianasolo B, Swezey T, Van D K, et al. Barriers to the use of modern contraceptives and implications for woman-controlled prevention of sexually transmitted infections in Madagascar. J Biosoc Sci 2008; 40(6):87993.

6. Asekun O E, Adebimpe W, Bamidele J, Odu O, Asekun O I, Ojofeitimi E. Barriers to use of modern contraceptives among women in an inner city area of Osogbo metropolis, Osun state, Nigeria, Int J Women H 2013;11(5):64755 . 
7. Tilahun T, Coene G, Luchters S, et al. Family planning knowledge, attitude and practice among married couples in Jimma zone, Ethiopia, PLoS one 2013;8(4): 1-8 (e661335).

8. Agha S, Fareed A, Keating J. Clinical training alone is not sufficient for reducing barriers to IUD provision among private providers in Pakistan. Reprod Health 2011; 30 (8):40-49

9. Omo-Agboja LO, Omo-Aghoja VW, Aghoja $\mathrm{CO}$, et al. Factors associated with the knowledge, practice and perceptions contraception in rural Southern Nigeria. GMJ 2009; 43(3):115-21.

10. Hock-Long L, herceg-Baron R, Cassidy AM, Whittaker PG. Access to adolescent Reproductive health services: financial and structural barriers to care.Perspective Sexual Reprod Health. 2003; 35(3) 144-47.

11. Whitley E, Ball J. Statistics review 4: Sample size calculations. Crit care 2002;6(4):335-341

12. Allagoa DO, Nyengdiki KT. Knowledge, attitude and practice of contraception among antenatal patients at the university of PortHarcourt Teaching Hospital,Port-Harcourt. The Nig Hlth J. 2011; 11(3): 89-92.

13. Olaleye DO. Ideal family size: A comparative study of numerical and non-numerical fertility desires of women in two sub-saharan African countries. DHS working papers No 7. Calverton, Maryland, USA: Macro International

14. Caldwell JC, Caldwell P. Cultural forces tending to sustain high fertility in tropical
15. Africa. PHN technical note 85-16, world bank, population, Health and Nutritional Department. 1985

16. Guttmacher institute/ United Nations population fund, Adding it up: The costs and benefits of investing in family planning and maternal and newborn health (Washington,DC:Guttmacher Institute) 2009

17. Ochako R, Mbondo M, Aloo S, et al.Barriers to modern contraceptive methods uptake among young women in Kenya: a Qualitative study. BMC Public health 2015; 15: 118-26

18. John B, Bruce J. The causes of unmet need for contraception and social content of Services. Studies in Fam Plann 1995;26(2):57-75.

19. Sedgh G, Hussein R. Reasons for contraceptive nonuse among women having unmet need for contraception in developing countries. Studies in fam plan 2014; 46(2):151-69.

20. Gyimah SO, Adjei JK, Takyi BK. Religion, contraception and method choice of Married women in Ghana. J Relig Health 2012; 51(4):1359-74

21. Ainsworth M, Beegle K, Nyamete A. The impact of women's schooling on fertility and contraceptive use: A study of fourteen subSaharan African countries. World bank economic review 1996. 10:85-122.

22. Briggs ND. Maternal health and illiteracy educate or die: A commentary. Lancet 1993:341:1063-64 